\title{
AHP AND DECISION MAKING ON THE USE OF CULTURAL HERITAGE IN RURAL TOURISM DEVELOPMENT IN LATVIA
}

\author{
Baiba Rivza, Laura Jeroscenkova, Peteris Rivza
}

Latvia University of Agriculture, Baiba.Rivza@llu.lv

\section{Abstract}

The preservation of cultural heritage has become an important component of government policies of the EU and, of course, Latvia. Along with the preservation of cultural heritage, the use of it is also important. The paper focuses on the problem of use of cultural heritage in developing rural tourism. The paper defined three scenarios for the use of cultural heritage in developing rural tourism. A decision on the choice of the most appropriate scenario was made based on an expert decision-making method - the Analytic Hierarchy Process (AHP).

Key words: cultural heritage, rural tourism, the Analytic Hierarchy Process

\section{Introduction}

The advantageous geographical situation of Latvia, its rich historical and cultural heritage as well as the untouched nature are preconditions for developing tourism. Rural tourism is an agricultural industry that enables local residents as well as foreign tourists to view Latvia's beautiful and historically important landscape.

Significant research studies on the development of rural territories, cultural tourism, the preservation and activation of cultural tourism and rural tourism have been done by both foreign and Latvian researchers (Liscova, 2011, Rivza,2001).

\section{Materials and Methods}

To make a decision on the best scenario for the use of cultural heritage in developing rural tourism, the authors employed a multi-criteria decision-making method - the Analytic Hierarchy Process (AHP) (Saaty, 1991, 2007). There were engaged seven experts who represented rural craftsmen, municipalities, rural tourism organisations, the Association of Rural Female Entrepreneurs and ministries.

According to the AHP, the experts, first of all, had to design a hierarchy, the first level of which involves a problem. After discussions, the problem was defined: the use of cultural heritage in developing rural tourism (Figure 1). This is Level 1 of the hierarchy.

Further, in developing the hierarchy, criteria groups are defined, which will be Level 2. In our case, there are five criteria groups: interests of residents, interests of entrepreneurs, local government interests, national interests and EU interests.

Further, the experts defined criteria for each criteria group, for example, the criteria group of interests of residents involved five criteria (: job opportunities at the place of residence, preservation of family craft traditions. extra revenue, preservation of cultural heritage for next generations, mentoring of the new generation.

Criteria for the other criteria groups were defined in a similar way The criteria compose Level 3 of the hierarchy However, at Level 4, which is the last one of the hierarchy, there are scenarios to be evaluated by the experts by employing all 25 criteria from all the criteria groups.

Further, the authors described three potential scenarios for the use of cultural heritage in developing rural tourism.

Scenario 1. The initiative of entrepreneurs, public organisations and residents

Scenario 2. The programme funded by national and regional institutions

Scenario 3. The EU fund for the preservation of cultural heritage

The experts start their evaluation from the hierarchy's top levels - from Level 2 -, i.e. evaluating the criteria groups. The experts compare the criteria groups in pairs and evaluate their mutual weight relative to the problem, i.e. Level 1. The experts' evaluations are expressed in numbers using a special 9-point scale (Saaty, 2007) and entered into the expert's evaluation table. A priority vector's coordinates and a consistency ratio are calculated for each expert's evaluation table.

The work of all the experts with regard to filling in the tables is organised in the same way, and priority vector coordinates and consistency ratios are calculated for all the tables. In conclusion, each expert's evaluations are summarised and a table of the global priority vector's coordinates is constructed, as well as necessary calculations are performed according to Formula 2.

Evaluations given by the seven experts are processed by calculating the arithmetic mean and dispersion for each evaluation. In charts, the dispersion is presented as amplitude, i.e. by means of the minimum and maximum values for each particular evaluation.

\section{Results and Discussion}

The experts evaluated the criteria groups almost equally, giving the priority to national $(0.27)$ and local government interests (Figure 2). The experts were unanimous on the significance of the criteria group for local government interests, which were indicated by the small dispersion, compared with the criteria group for national interests (Figure 2). 


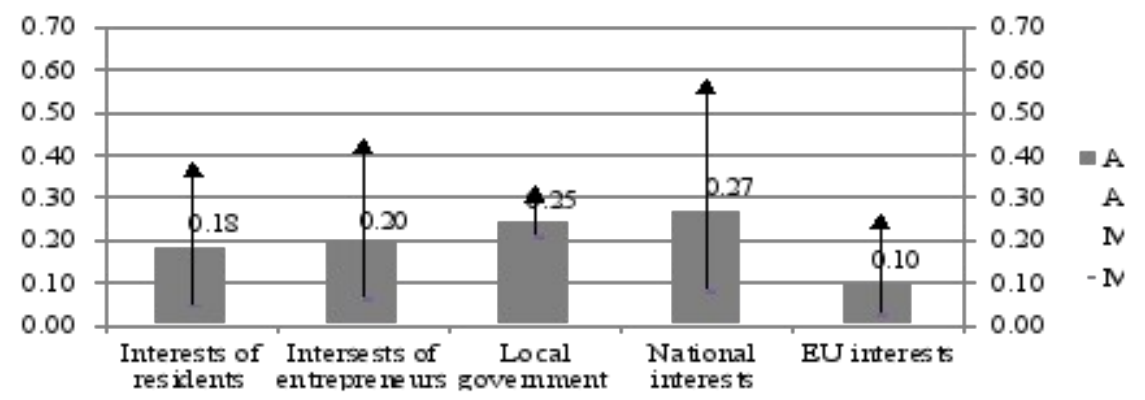

Source: authors' construction based on the hierarchy analysis

Figure 2. Evaluations of the criteria groups by the experts for the scenarios for the use of cultural heritage in the development of rural tourism

Based on the above-mentioned criteria, the third scenario was named the "EU fund for the preservation of cultural heritage". The average vector coordinate for the evaluations by the experts was 0.42 .

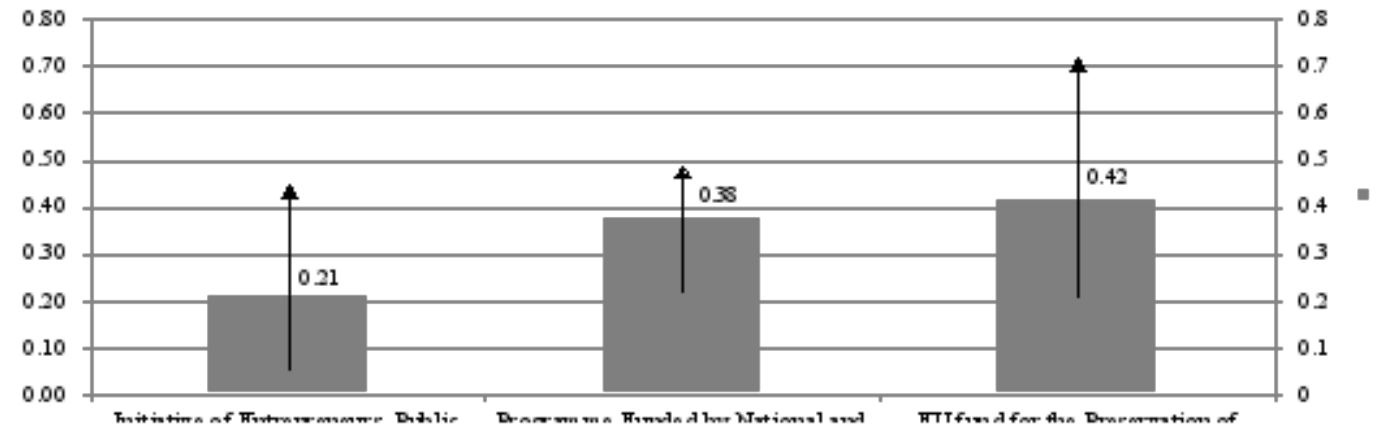

ce: authors' construction based on the hierarchy analysis

Figure 3. Evaluations by the experts for the scenarios for the use of cultural heritage in the development of rural tourism

Yet, the expert evaluations have a large dispersion, and it means that the opinions were different. A lower evaluation was given to Scenario 2, the programme funded by national and regional institutions $(0.38)$, while the dispersion was smaller (Figure 3). The initiative of entrepreneurs, public organisations and residents, i.e. the current model, was evaluated the lowest, at only 0.21 . The large dispersion in this case too pointed to the difference in the experts' opinions. It means that national and EU financial support is needed in order that a significant change takes place in the use and preservation of cultural heritage.

The final conclusion on the fact the last two scenarios for the use of cultural heritage in the development of rural tourism: the programme funded by national and regional institutions and the EU fund for the preservation of cultural heritage have similar evaluations, with the latter one having a slightly greater evaluation. Source: authors' construction based on the hierarchy analysis

\section{Conclusions}

1. Three development scenarios were put forward for the use of cultural heritage in the development of rural tourism: the initiative of entrepreneurs, public organisations and residents; the programme funded by national and regional institutions; the EU fund for the preservation of cultural heritage.

2. Based on the criteria set in the hierarchic analysis, the scenario EU fund for the preservation of cultural heritage was evaluated as the most appropriate.

\section{Acknowledgement}

The preparation of the paper was supported by the National Research Programm 5.2. Economic Transformation, Smart Growth, Governance and Legal Framework for the State and Society for Sustainable Development-a New Approach to the Creation of a Sustainable Learning Community, Project EKOSOC_LV

\section{References}

1. Liscova A., Rivza B., Kruzmetra M.. (2011) Farm Diversification Models: Causes and Tendences. Proceedings of the International Scientific Conference "Economical-Managerial aspects of Regions and Organizations Sustainable Development.” April 8-9, 2011, Klaipeda, Klaipeda University, 155.-159.p.

2. Rivza P., Rivza B., Ramute L (2001), Experience in the Use of the Analytic Hierarchy Process in Latvia. Humanities and Social Sciences. Latvian countryside today. 1 (30)/ 2001. University of Latvia, pp. 15-23.

3. Thomas L.Saaty (2007), Decision Making for Leaders, RWS Publ.,384 pp. 
4. Thomas L.Saaty, Kevin P. (1991). Kearns Analytic Planning: The Organization of Systems, RWS Publ., 2008 pp. 